\title{
RELATIVE ADVANTAGES OF TOOTHED AND SMOOTH CORE ARMATURES.
}

BY ALTON D. ADAMS.

The merits of different methods of construction in dynamo electric machinery, as in other lines, must evidently be decided by their comparative costs, all else being equal.

Although questions concerning the relative merits of toothed and smooth core armatures have long been discussed, very little seems to have been written to show whether actual saving in cost may be effected by one construction over the other, when employed to produce the same results. The practice of dynamo builders in this country, and abroad, embodies both types, and the history of the art records many changes from each to the other. In view of the above, the inquiry, whether in the light of present facts any saving can be effected by the use of toothed core armatures, seems of interest.

The limits of this paper do not permit consideration of this question in connection with all classes of electrical machinery, and its bearing on direct current constant pressure machines only, will be taken up.

The principal disadvantages of toothed, compared with smooth core armatures, are greater first cost, large change of lead, and excessive sparking, when used with too short air-gaps, and the production of heat in pole-pieces; their advantages are, that inductors are positively driven, large solid inductors protected from eddy currents, and that a reduction may be made in the length and consequent magnetic resistance of the air-gap. Change of lead may be fixed within any desired limits, and sparking abated 
by such proportions of air-gap and teeth, as give them sufficient magnetic resistance.

Heat in pole-pieces may be reduced by their lamination, by the use of very narrow teeth and slots, by forms of teeth that present a nearly continuous surface of iron to the pole-pieces, and still more, by the use of openings in core disks which do not cut through their outside surface, or a continuous magnetic sheath outside the teeth. For any given form of tooth, the heating of pole-pieces is less, the longer the air-gap.

The mechanical strength of armature teeth, as usually employed, is far in excess of that required to hold inductors in position, even under conditions of short-circuit, and driving-pins inserted in the core, at proper intervals, are much cheaper and take up less valuable room on the armature circumference.

Either teeth or substantial driving-pins are, of course, preferable mechanically to the slender bits of hard fibre which have been much used, and frequently give way under the heavy strains to which large generators are subject.

When large wires or copper rods are used as inductors, their protection from eddy currents is an important matter, but proper stranding of inductors reduces the eddy loss in them, when used on smooth cores, to a very small amount, and has the further important advantage that inductors may be bent into the proper shape at armature ends, and the joints necessary when rods are used, avoider. The chief possible advantage, then, to be gained by the use of toothed armatures, is through a reduction in the length of the air-gap, and the consequent reduction in the ampere-turns required on field magnet, weight of copper, or energy in winding, and the length and weight of iron core. To make this advantage available, it must be practical to use air-gaps shorter than are required for insulation, winding and clearance.

As is well understood, the armature winding of a dynamo or motor, in operation, has a magnetizing action which is measured in ampere-turns for a bipolar machine, by one quarter the product of all the inductors of the armature, into the total armature current. The ampere-turns on the armature evidently tend to set up a flow of magnetism, having a complete circuit through the armature core, twice across each air-gap and through the iron of pole-pieces.

About half the ampere-turns furnished by the inductors under pole-pieces, evidently act against the field ampere-turns in 
each air-gap at the polar tips, and the ratio between the armature and field ampere-turns at this point, necessary to give sparkless reversal there, must determine whether the required magnetic resistance be greater or less than that of an air-gap long enough for insulation, winding, and clearance with a smooth core armature.

As an armature coil in an operating dynamo or motor passes under the brush, the current flowing in it must stop, and one in the opposite direction be set up; and if this action is to be accomplished without sparking, a sufficient electromotive force must be provided in the coil while in direct contact with the brush. In the ordinary dynamo or motor, magnetism forced across the path of the coil, by the field ampere-turns expended in air-gap, must provide this reversing electromotive force.

The data of a number of smooth core armature machines of different make, show ratios of field to armature ampere-turns in air-gap, of from about one and one-half to one, to two and onehalf to one, and the writer's experience is that a ratio of two to one will give sparkless operation at full load, with brushes set just outside pole corners.

It is a matter of common experience that the ratio between field and armature ampere-turns in the air-gap may be so reduced, even in machines with smooth core armatures, as to require excessive change of lead to secure even approximate freedom from sparking. If it be desired therefore to build machines having an expenditure of field ampere-turns in the air-gap not much greater than those of the armature, we need not resort to toothed cores.

Take, for example, the case of a 260-ampere dynamo, with 120 inductors on its armature in one layer; an air-gap induction of 25,000 lines per square inch, and 80 per cent. of inductors under the pole-pieces.

An air-gap of .45 inch between the armature core and each polepiece will be sufficient for insulation, winding and clearance, and the field armature turns expended in each air-gap will therefore be 3523 , while the armature ampere-turns, active under each pole tip, will be 3,120 . A considerable change of lead and sparking can be readily predicted for this machine.

In some types of small machines, the room required by insulation, winding and clearance, makes the air-gap longer than necessary for sparkless operation, and in such machines the utility of 
teeth seems to depend on their cost, compared with the saving to be effected by their use.

As the ampere-turns, furnished by the inductors under any pole-piece grow less, in a machine of given capacity, when the number of poles is increased, very short air-gaps may be used, if the number of poles is sufficiently large.

As, however, an increase in the number of poles usually makes a machine of given capacity more expensive, the question at once comes up, to what extent the number of poles may be increased without a greater expenditure than the saving to be effected.

In large multipolar machines of four to six poles, such as are commonly used, the length of air-gap required for sparkless operation, is considerable, and those who have watched the development of these machines with toothed core armatures during the last four or five years, have seen the air-gaps gradually widen until machines of this character are not hard to find, in which the copper inductors between the teeth could be taken out, wound outside the teeth, and still leave room enough for good clearance. Additional mechanical security, of course, furnishes a considerable argument for the use of teeth in very large slow speed machines.

A number of devices have been suggested from time to time, to enable toothed core armatures to be used with short air-gaps, and the consequent saving in iron and copper effected. No machines with these devices, however, have yet stood the test of time and competition with those of ordinary type, and they have yet to prove their ability to produce results, as at present attained at a less cost.

The seeming opportunity to save material by the use of toothed armatures is very attractive, and we cannot but hope it may some day be practical; in the light of present knowledge, however, there seems little to be gained by their use in medium and large bipolar machines.

Worcester, Mass, May 9, 1894. 


\section{Discussion.}

Mr. A. E. W IENER:-After enumerating the advantages and disadvantages of toothed armatures, the author comes to the conclusion that the chief advantage of toothed armatures over smooth ones is the reduction of the length of the air-gap, and the consequent decrease of the exciting power required. But he left out one very important disadvantage, namely the leakage through the armature core, caused by a portion of the lines entering the teeth, and passing through the armature without eutting the conductors. From a large number of machines I have found that, if otherwise well designed, the disadvantage of this core-leakage just about cancels the advantage of the air-gap reduction; for in order to allow for the waste armature-field due to this core-leakage, the exciting power has to be increased in about the same degree, as the lessening of the magnetic resist-

TABLE I.

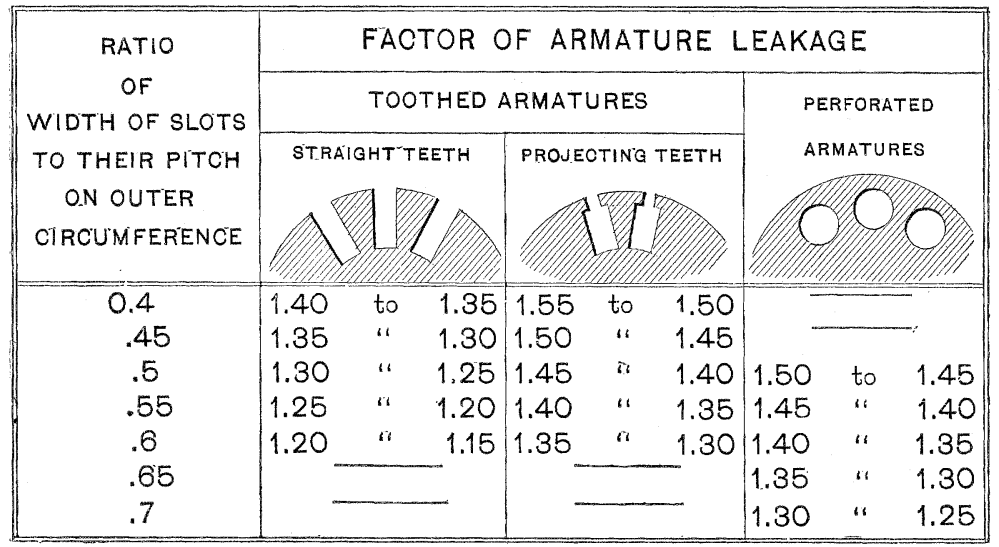

Core Leatkage in Toothed and Perforated Armatures.

ance of the gap would otherwise decrease it. The chief advantage claimed by the author, consequently, is thus only an imaginary one, and, indeed, there are no such striking advantages in either of the two kinds of armatures as to make any one of them superior in all cases over the other. On the contrary, it is really a matter of choice, with reference to the special application of the machine to be designed, whether to employ a smooth or a toothed armature. In the case of a slow speed motor, for instance, as used in single-reduction, and in gearless street car motors, where great torque is wanted, a toothed armature core will offer better advantages, and its somewhat higher cost of manufacture has to be overlooked. When, on the other hand, the machine is to be used as a generator for very low potential (electroplating dynamos, etc.), a smooth armature core is preferable.

From quite a number of machines I have averaged the follow- 
ing table of armature leakage in toothed, and perforated armatures, to appear in a series of articles entitled "Practical Notes on Dynamo Calculation," and commenced in this week's issue of the Electrical World.

The amount of the core leakage depends upon the ratio of the width of the slots to the width of the teeth, and, if the armature is otherwise properly designed, will rary within the limits shown in Table I.

On account of this core leakage, the tield-densities obtained in toothed and perforated armatures are considerably smaller than in smooth core machines, as can be noted from the following table which gives the practical field densities of various dynamos, derived from the data and tests of abont two hundred of the best modern dynamos:

From Tables I and II follows the practical truth of my above

TABLE II.

Field Densities, in Lines of Force per square Centimeter

\begin{tabular}{|c|c|c|c|c|c|c|c|c|c|c|c|c|c|}
\hline \multirow{4}{*}{ 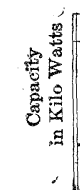 } & \multicolumn{6}{|c|}{ Bipolar Dynamos } & \multicolumn{6}{|c|}{ Multipolar Dynamos } & \multirow{4}{*}{ 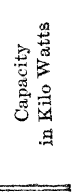 } \\
\hline & \multirow{2}{*}{\multicolumn{2}{|c|}{$\begin{array}{l}\text { Smooth } \\
\text { Ármature } \\
\text { Core }\end{array}$}} & \multicolumn{4}{|c|}{ Toothed Armature Core } & \multirow{2}{*}{\multicolumn{2}{|c|}{$\begin{array}{c}\text { Smooth } \\
\text { Armature } \\
\text { Core } \\
\\
\end{array}$}} & \multicolumn{4}{|c|}{ Toothed Armature Core } & \\
\hline & & & \multicolumn{2}{|c|}{$\begin{array}{l}\text { Straight Teeth } \\
\end{array}$} & \multicolumn{2}{|c|}{ Projecting Teeth } & & & & Teeth & & & \\
\hline & \begin{tabular}{|c|} 
Cast \\
1ron \\
Polepieces \\
\end{tabular} & \begin{tabular}{|l|} 
Wr't Iron \\
or Stted \\
Polepieces \\
\end{tabular} & \begin{tabular}{|c|} 
Cast \\
Iron \\
Pólopiecese \\
\end{tabular} & \begin{tabular}{|l|} 
Wr't Iron \\
or Steed \\
polepieceses
\end{tabular} & $\begin{array}{c}\text { Cast } \\
\text { Iron } \\
\text { Polepieces } \\
\end{array}$ & $\begin{array}{l}\text { Wr't Iron } \\
\text { or Steel } \\
\text { poleplieces } \\
\end{array}$ & $\begin{array}{c}\text { Cant } \\
\text { Iron } \\
\text { Polepieces } \\
\end{array}$ & 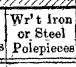 & $\begin{array}{c}\text { Cant } \\
\text { Iron } \\
\text { Doirepieces } \\
\end{array}$ & $\begin{array}{l}\text { Wr't Iron } \\
\text { or Bteel } \\
\text { polepieces } \\
\end{array}$ & \begin{tabular}{|c|} 
Cast \\
Iron \\
Polopieces \\
\end{tabular} & \begin{tabular}{|l|}
$\begin{array}{l}\text { Wr't Iron } \\
\text { oor Steel } \\
\text { Polepiecea }\end{array}$ \\
\end{tabular} & \\
\hline d & 1550 & 2300 & 1250 & 1850 & & & 2150 & 3100 & 1850 & 2800 & $\longrightarrow$ & & \\
\hline .25 & 1850 & & 1550 & 23 & & & 500 & 3700 & 2150 & 3250 & & & \\
\hline & 2150 & 3100 & 1850 & & - & & 2800 & 4200 & 2500 & 3700 & & - & 5 \\
\hline 1 & 2300 & 3400 & 2000 & 2950 & 1250 & 1850 & 2950 & 4350 & 2650 & 3850 & 1550 & 2300 & \\
\hline 2.5 & 2500 & 3700 & 50 & & & & 00 & 4500 & 2800 & 4000 & 1700 & 2500 & .5 \\
\hline 5 & 2650 & 3850 & 2300 & 34 & & & 3250 & 4700 & 2950 & 4350 & 1850 & 2800 & \\
\hline 7.5 & 300 & & 2500 & & 1 & 2500 & 3400 & 5000 & 3100 & 4700 & 2000 & 8100 & .5 \\
\hline 10 & 50 & & 2650 & & & 2800 & 3700 & 5400 & 3250 & 5000 & 2150 & 3300 & 0 \\
\hline 25 & & & 2800 & & 000 & 3100 & 4000 & 5900 & 3400 & 5400 & 2300 & 3500 & \\
\hline 50 & & & 3100 & & & 34 & 48 & & 3550 & 5900 & 2500 & 3700 & 50 \\
\hline 10 & 00 & 600 & 3400 & 5100 & 2500 & & 47 & 6800 & 3850 & 6200 & 2650 & 3850 & 100 \\
\hline 200 & & & 3700 & & & 42 & 5000 & & 4200 & 6500 & 2800 & 4000 & 200 \\
\hline 300 & 4700 & $\gamma 000$ & 4200 & 6200 & 3100 & 4700 & 5400 & 7750 & 4500 & 6800 & 2950 & 4850 & 300 \\
\hline & 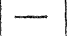 & - & - & $\longrightarrow$ & - & $=$ & 5900 & 8200 & 4800 & 7200 & 3100 & 4700 & 500 \\
\hline & $\longrightarrow$ & - & - & - & & $\longrightarrow$ & 6400 & 8700 & 5100 & 7500 & 3400 & 5000 & 1000 \\
\hline & & - & & 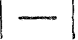 & & & 7000 & 9300 & 5400 & 7800 & 8700 & 5400 & 2000 \\
\hline
\end{tabular}

statement, viz., that about the same exciting power, or same number of ampere-turns will be required in both types of armatures; for, also, the reduction of the gap resistance, if the radial depth of the armature core is properly dimensioned, depends upon the ratio of the width of the slots to the width of the teeth.

Mr. Steinmetz:-I was somewhat astonished when hearing this paper, in-so-far as the conclusions drawn therein. They are to a large part just opposite to what I concluded by theoretical reasoning, and found proved by practical experience.

What I intend to say, however, refers only to larger machines, machines of some hundreds of kilowatts. With regard to the

1. See Electrical World, xxiii, p. 675. (May 19, 1894.) 
superiority of the toothed armature in these machines, I may first point to the fact that neither in this country nor in any other country is any large power generator running which will commutate sparkless, from no load to full load and overload, without shifting of the brushes, as it is required for instance in railway generators, where, due to the constant and sudden fluctuations of load, a shifting of the brushes is impracticable. On the other hand, hundreds of thousands of horse power of machines with toothed armatures, which will fulfil this condition of sparkless commutation without shifting of the brushes, are in daily use in this country alone. The reason for this superiority is, that the distortion of the field in a properly designed machine with toothed core is very much less than in the machine with smooth core. You can indeed by shifting the brushes get sparkless commutation in smooth core machines also, and you have in smooth. core machines the decided advantage of lower self-induction.

But if you have to commutate without shifting the brushes, smooth core machines are out of competition.

The advantage of the toothed armature is not so much the lesser ampere-turns consumed in the gap. In larger machines you cannot do anything like what is proposed here, to use .45 of an inch as total clearance from iron to iron. This would give a clearance of about $\frac{1}{16}$ of an inch from the binding wires of the armature to the iron of the field poles, which may be all right for a small machine, but not for a large power generator. In such a machine, with toothed core, the clearance between armature and field is determined by mechanical reasons only, and is from $\frac{1}{4}$ inch to $\frac{1}{2}$ inch from the head of the armature teeth to the field poles.

The foremost feature of the modern toothed core power generator is the lesser distortion of the field, as the following diagram will show.

Let, in Fig. 1, be represented the м. м. F. diagram of a smooth core machine. The field pole $\mathrm{P}$ and the armature $\mathrm{c}$ with the armature conductors are shown in development in drawn lines. The м. м. F. exerted upon the air-gap by the field spools is represented by the dotted line F. The м. м. F. exerted upon the air-gap by the current in the armature conductors (armature reaction) is represented by the dotted line $\mathrm{A}$, which is positive at the trailing, negative at the leading pole-horn, in a generator. Thus the total or resultant M. M. F. acting upon the air-gap is represented by the dotted line $\mathrm{T}$, and proportional thereto, in a smooth core machine, is the magnetic density in the air-gap. As seen, the magnetic gap density is very much less at the leading pole-horn, where it is needed for sparkless commutation, than at the trailing horn, where it is not needed. At the same time the field has shifted considerably.

Now consider the toothed core machine, in Fig. 2. If the 
total effective gap, that is the space between pole-face and foot of slots, the same M. M. F., F, is exerted by the field spools-that is, the tooth density is appropriately high-the total or resultant м. M. F., T, is again the same as with the smooth core in Fig. 1. But here the magnetic density в is not proportional to the м. м. F. $\mathrm{T}$, but $\mathrm{B}$ varies very much less than $\mathrm{F}$, due to the effect of magnetic saturation, and thus the gap density is very much more uniform, as shown by dotted line $\mathrm{B}$ in Fig. 2, and the field has shifted very little. Thus the machine in Fig. 2 will commutate sparkless from no load to full load, without shifting the brushes, while machine, Fig. 1, will spark furiously if the brushes are not shifted with varying load.

On the other hand, due to the small self-induction of the armature conductors, the smooth core machine is very desirable for lighting machines where very large currents have to be commutated at low voltage between the commutator bars, and the load does not fluctuate suddenly by hundreds or thousands of amperes.

But for railway generators, where you have to use larger voltage between commutator bars, and where you have to leave

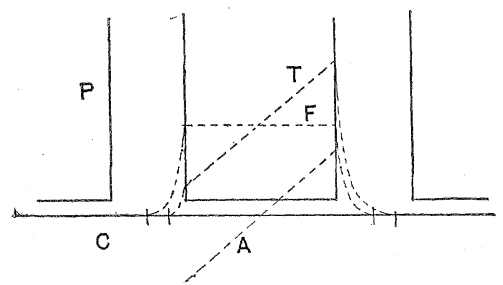

Fig. 1.

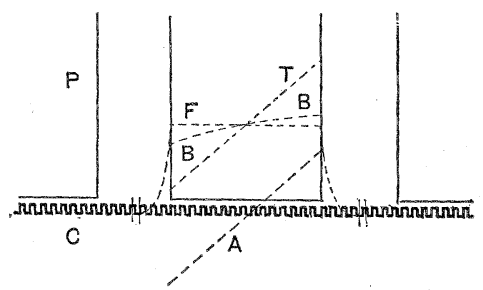

FIG. 2.

the brushes in the same position under all loads, there you must use the toothed armature. You cannot make a railway generator work decently with a smooth core.

Mr. Gano S. Dunn:- It is true that there must be a definite magnetic resistance in the gap to enable the machine to operate sparklessly, but if you will consider the smooth and the toothed armatures, you will find that with the former the reluctance of the air-gap is constant, and with the latter it increases as a result of armature reaction, with load. This is due to the variable reluctance of the iron which constitutes the teeth, and which at saturation approaches air, giving a low resistance and a bigh resistance air-gap for light and full loads respectively. To put it a little clearer, the effect is similar to the case of a smooth armature run with an air-gap which as the load increases, lengthens, and thereby preserves sparkless commutation. For the above reasons a toothed armature air-gap can have a lower average reluctance than that of a smooth armature. The reluctance of the latter is constant and always at its maximum value.

In small machines however, the above considerations do not 
apply, because sparklessness need not be dependent upon a fringe at the pole tip to reverse the current in the coil. Machines may be lighter and neater which depend on other means for sparkless commutation. If for instance we cause the resistance of the carbon brushes to make the current reversal, then we can greatly diminish the reluctance of our air-gap and use a proportionately smaller field current and weight of copper, and secure important advantages in efficiency and lightness.

Another point which at present is not of so much importance, is that with dynamotors or direct current transformers, there is practically no armature reaction or tendency to spark, and consequently no necessity for reluctance in the air.gap. The toothed armature allows us to take advantage of these conditions in a manner irnpossible with an armature which of necessity demands a high reluctance air-gap.

With regard to mechanical advantages, the toothed armature with wires embedded and held firmly in slots, is so superior to the smooth armature wound with wire held on by various devices, that even were the toothed armature more expensive, which I am not ready to admit, it would be preferable.

Mr. WM. STanley :-I would like to ask the last speaker if he does not consider that the extra self-induction due to the armature teeth, especially in the larger machines, is the cause of the sparking that we see on the street railway generators, and that if it were possible to arrange the wires on the circumference of the machine-I do not say that it is mechanical to do sobut if it were possible to do it, if the machine would not be more sparkless? Does not the self-induction of the buried wire in the iron core increase the sparking from one commutator bar to another?

Mr. Dunn:-There is no question that burying the wire increases the self-induction, and if the openings at the top of the slot are too narrow, or if as in the case of the Wenstrom armature, there is no opening, this is a very serious defect, but the openings can be so proportioned that the increase of self-induction while a disadvantage, is not serious.

Mr. Stanley:-Is it not the principal disadvantage?

Mr. Dunn :-Yes, I should consider that it was. The paper alleges that the toothed armature requires more material; that this is true, generally speaking, I do not agree. I think the self-induction is the greatest disadvantage.

Mr. Steinmetz:- I do not think that the representation of the toothed core by a gap, which widens with the increase of a load quite meets the point. What I wanted to show by the diagram is, that the distribution of the magnetic density at the gap at full load is not proportional to the distribution of the resultant M. M. F., but is very much more uniform, due to the effect of saturation, and therefore the field does not shift seriously, and the brushes can be left in the same position at all loads, in the fringe of the 
reversed field, which is required to overcome the self-induction of the current in the coil which is being commutated. For if you have to reverse hundreds of amperes, backed up by a large E. M. F. of self-induction, you have to have forced commutation.

It is to get rid of the shifting of the field, due to the armature reaction, which really constitutes the advantage of the toothed armature, which enables us to get a very much higher efficiency with the toothed armature than with the smooth core.

Mr. C. N. Black:- There is another point I would like to make and that is, it seems to me practically impossible to build dynamos of large units, such as we are building now for railway work, and use a smooth armature, on account of the great losses we would get from eddy currents set up in the conductors thernselves. The size of the conductors is such, that if they are made solid, that loss conld not be neglected and would be a source of a good deal of heat, at the same time decreasing the efficiency of the machine quite materially. If we laminate the conductors it makes a very difficult construction, in fact, almost impracticable. There is one other point that I do not think has been mentioned, and that is in series motors, where we use a toothed armature, we get a much more constant speed. At light loads, the teeth being worked at a low point of magnetization, offer but little reluctance to the flux through the armature, while at heavy loads the teeth become saturated, and in consequence add a considerable reluctance to the inagnetic circuit, thereby cutting down the induction from what it would be if increased in proportion to the increased number of ampere-turns on the field, consequently we get a motor that is much nearer self-regulating than one with the smooth core armature.

Mr. A. E. Kennelly:- The point has not been brought out, I think, that if you have a toothed armature, you can much more readily ventilate the armature from within, whereby you can carry off the heat from the surface far more efficiently than if the armature is entirely covered by wire.

Mr. OberLin Suith :- I would like to hear an expression of opinion as to the relative cost of a toothless ring and that toothed ring.

Mr. Steinmetz:- I think the question of ventilation is not such a drawback against the smooth core machine, because the modern design of lighting machines, which are smooth cores for the commutation of very large currents, are ventilated also by ventilating spaces between the armature conductors. and even the twisting of the conductors is not so difficult, but is done in smooth core armatures. I have some machines being built which will have these twisted conductors, and which will exclude eddy currents almost perfectly-smooth core machines for low voltage, of 400 kilowatts. With regard to the relative cost of both types. of machines, it is difficult to state it, because they are different. types of machines for different purposes, and thus cannot be compared properly. 
Smooth armatures are built for lighting where the toothed armature does not offer any advantages, where you have very low speed, large conductors and low voltage from bar to bar, while the ironclad is perfect as a high voltage power generator. Thus you have never built two machines, one smooth core and one ironclad, for the same purpose and of the same dimensions. In general I am of the opinion that the toothed armature is the cheaper one.

[The meeting then adjourned for the day.]

In the evening the Annual Dinner took place at the Hotel Metropole, at which 76 members and guests were present. 